\title{
MODEL USAHATANI KENTANG DI HULU DAERAH ALIRAN SUNGAI (DAS) CITARUM (Studi Kasus di Koperasi Pertanian Pesantren Al-Fatah)
}

\section{POTATO FARMING MODEL IN CITARUM RIVER FLOWS (DAS) AREA (Case Study in Al-Fatah Islamic Boarding School Cooperative)}

\author{
Raissa Fidela Andrini*, Iwan Setiawan \\ Program Studi Agribisnis, Fakultas Pertanian,Universitas Padjadjaran \\ *E-mail: fdlaraissa@gmail.com \\ (Diterima 18-01-2020; Disetujui 16-03-2020)
}

\begin{abstract}
ABSTRAK
Kecamatan Kertasari di Kabupaten Bandung merupakan lahan kritis terluas. Lahan kritis tersebut terjadi karena perubahan penggunaan lahan hutan menjadi pemukiman dan budidaya tanaman semusim. Tujuan yang ingin dicapai dalam penelitian ini adalah untuk mendeskripsikan model usahatani semusim, yaitu kentang di hulu DAS Citarum yang dibudidayakan terus menerus. Desain penelitian yang digunakan dalam penelitian ini adalah kualitatif dan teknik penelitian yang dilakukan adalah studi kasus. Model usahatani di Kecamatan Kertasari merupakan pertanian konvensional yang masih menggunakan alat pertanian dengan menggunakan tenaga manusia dan hewan. Koppotran memiliki lahan sendiri dan lahan sewa yang diiringi dengan teknik konservasi di lahan miring. Tanaman kentang sebenarnya tidak ramah lingkungan karena merusak lingkungan seperti erosi. Kopottran melaluikan kegiatan penghijauan kembali dengan melakukan kegiatan tumpangsari dengan tanaman kopi dan membersihkan DAS Citarum. Masyarakat harus lebih meningkatkan kepedulian terhadap kelestarian lingkungan dengan reboisasi di sekitar pemukiman dan DAS Citarum.
\end{abstract}

Kata Kunci : Lahan Kritis, Model Usahatani, Tanaman Kentang

\section{ABSTRACT}

Kertasari Subdistrict is the area with the largest critical land in Bandung Regency. Critical land is due to changes in the use of forest land into the cultivation of annual crops and settlements. The objective to be achieved in this research is to describe the seasonal farming model, namely potatoes in the upstream Citarum watershed which are cultivated continuously. The research design used in this research is qualitative and the research technique used is case study. The farming model in Kertasari Subdistrict is still conventional farming, which uses agricultural tools and uses human and animal power. Koppotran has his own land and rental land accompanied by conservation techniques on sloping land. Potato plants are actually not environmentally friendly because they damage the environment such as erosion and for reforestation Kopottran is doing intercropping with coffee plants and cleaning the Citarum watershed. The community must increase their awareness of environmental sustainability by reforestation around the settlement and Citarum watershed.

Keywords : Critical land, Farming models, Potato plant 


\section{PENDAHULUAN}

Hortikultura merupakan salah satu sub sektor pertanian yang mempunyai potensi sangat penting untuk mendorong peningkatan kesejahteraan petani, ekspor, dan ekonomi daerah (Deputi Bidang Koordinasi Pangan dan Pertanian, 2018). Salah satu komoditas hortikultura yang menjadi perhatian untuk dikembangkan yaitu kentang (Solanum tuberosum). Pada tahun 2014, kentang merupakan komoditas yang mempunyai kontribusi terbesar kedua terhadap produksi sayuran nasional, yaitu sebesar 11,31\% (Ditjen Hortikultura, 2015).

Kabupaten Bandung merupakan produsen dengan nilai produksi kentang terbesar di Jawa Barat bila dibandingkan dengan kabupaten-kabupaten lainnya (Dinas Pertanian Jawa Barat, 2017). Sentra produksi kentang tersebar di beberapa kecamatan salah satunya di Kecamatan Kertasari. Sentra produksi lainnya berada di Pangalengan, Cimenyan, Cilengkrang, Cikancung, Pacet, Ibun, Rancabali, dan Pasirjambu.

Kecamatan Kertasari adalah hulu dari daerah aliran sungai (DAS) Citarum yang merupakan sungai terpanjang di Jawa Barat. Lokasi ini tentu menjadikan tempat tersebut sebagai salah satu daerah konservasi tanah yang kelestariannya harus dijaga. Namun, pada kenyataannya berdasarkan data dari Dinas Pertanian, Kehutanan dan Perkebunan Kabupaten Bandung tahun 2015, Kecamatan Kertasari merupakan daerah terluas dengan lahan kritis (Fauziah, 2016). Ketidaksesuaian pengelolaan lahan pertanian telah menimbulkan permasalahan lingkungan terutama pada lahan budidaya pertanian di kawasan hulu DAS Citarum.

Penerapan teknik konservasi air dan tanah yang kurang intensif, erosi yang diakibatkan oleh penurunan lahan, kurangnya penutup lahan yang bersifat tanaman lindung, serta kesadaran petani yang rendah dalam melestarikan lingkungan adalah faktor-faktor penyebab terjadinya penurunan kualitas lingkungan. Terdapat beberapa cara untuk mengatasi permasalahan di hulu DAS Citarum agar tidak menjadi kritis. Pemerintah telah mengupayakan pelestarian lingkungan melalui sektor pertanian yang mampu mengurangi dampak negatif akibat rusaknya DAS Citarum dan penerapan teknik usahatani konservasi melalui proyek DAS.

Kegiatan tersebut dilakukan melalui peningkatan kesadaran dan pola pikir petani dalam menerapkan tata cara konservasi tanah dan air pada usahatani 
di daerah lahan-lahan kritis di lahan perkebunan. Pelibatan masyarakat melalui penyuluhan yang berkelanjutan terhadap petani dengan tujuan untuk meningkatkan tutupan vegetasi dengan tanaman yang bersifat konservatif namun tetap produktif yang dapat meningkatkan pendapatan dan kondisi sosial ekonomi petani (Direktorat Perluasan dan Pengelolaan Lahan Direktorat Jenderal Prasarana dan Sarana, Kementerian Pertanian, 2015).

Salah satu koperasi yang mengelola budidaya kentang di Kecamatan Kertasari ialah Koperasi Pertanian Pesantren (Koppotran) Al-Fatah, dan produksi terbesar di Koppotran Al-Fatah adalah komoditas kentang yang terletak di Desa Cikembang, Kecamatan Kertasari, Bandung, Jawa Barat. Keikutsertaannya dalam memproduksi kentang dari tahun 2005 memberikan dampak positif dalam hal memproduksi kentang yang unggul. Usahatani kentang granola dengan varietas G2 dan G3 yang merupakan program unggulan Koppotran Al-Fatah. Koppotran Al-Fatah mempunyai lahan untuk budidaya kentang di PTPN VIII dan lahan sendiri. Koppotran menjalankan usahatani di daerah berlereng yang rawan akan terjadinya erosi apabila tidak diiringi dengan teknik konservasi lingkungan dan dapat merusak lingkungan di daerah sekitarnya sehingga kentang tersebut berpotensi tidak berkelanjutan.

\section{METODE PENELITIAN}

Objek yang diteliti pada penelitian ini adalah Model Usahatani Kentang di hulu DAS Citarum (Studi Kasus di Koperasi Pertanian Pesantren Al-Fatah, Kecamatan Kertasari). Desain penelitian yang digunakan dalam penelitian ini adalah kualitatif dan teknik penelitian yang dilakukan adalah studi kasus. Triangulasi merupakan sebagai teknik pengumpulan data yang bersifat menggabungkan dari berbagai teknik pengumpulan data dan sumber data yang telah ada. Miles dan Huberman dalam Sugiyono (2012), mengemukakan bahwa aktivitas dalam analisis data kualitatif dilakukan secara interaktif dan berlangsung secara terus menerus sampai tuntas, sehingga datanya sudah jenuh.

\section{HASIL DAN PEMBAHASAN}

\section{Keragaman Usahatani Kentang di}

\section{Koperasi Pertanian Al-Fatah}

Status kepemilikan lahan yang digunakan untuk melakukan usahatani kentang yaitu milik sendiri dan sewa lahan. Koppotran memiliki lahan pribadi 
berkisar 10 ha terdiri atas 1,5 ha di Desa Cikembang, 3 ha di Bukatanah, 3 ha di Pacet, dan 2,5 ha di Desa Cibeureum. Sedangkan yang bekerjasama dengan lembaga lain sebesar 2 ha di lahan PTPN VIII. Tenaga kerja tambahan dalam usahatani kentang dibutuhkan jika para petani kentang tidak sanggup mengerjakannya sendiri. Jika membutuhkan tenaga kerja, maka petani kentang akan meminta bantuan kepada PPL atau pekerja umum seperti buruh tani, POPT atau petugas organisme pengganggu tanaman, THR atau petugas honorer dan PPS atau penyuluh petani swadaya yang sukarelawan tidak diupah sama sekali untuk membantu budidaya kentang.

Tenaga kerja untuk melakukan budidaya sebanyak 30 orang yang terbagi di berbagai lahan milik koppotran. Waktu kerja dari jam 07.00-12.00 WIB untuk sesi pertama; sedangkan sesi kedua dari jam 12.00-16.00 WIB. Tenaga kerja umum diupah dalam satu sesi sebesar Rp $50.000 \mathrm{HOK} / \mathrm{L}$ untuk laki-laki; sedangkan upah untuk wanita Rp 35.000 Hok/L. Tenaga kerja selain buruh tani, ada pula tenaga kerja dari pesantren yaitu santri yang ikut serta dalam sortir pembenihan kentang di gudang. Koppotran memiliki modal usahatani kentang yang didapatkan dari milik pribadi dan tidak meminjam kepada pemodal siapapun. Berdasarkan aktivitas tersebut, maka petani dituntut memiliki pengalaman, pengetahuan dan keterampilan yang mumpuni agar bisa mengelola usahatani yang baik. Koppotran bahwa mengelola usahatani kentangnya dibantu oleh Japan International Cooperation Agency (JICA) di sektor budidaya kentang, tetapi peran keluarga ikut andil dalam peran budidaya kentang.

\section{Subsistem Agribisnis Budidaya Kentang}

1. Pengadaan dan distribusi input

Koppotran Al-Fatah menggunakan benih dengan varietas G2 dan G3. Benihbenih tersebut dapat digunakan dua kali dalam pemakaian budidaya kentang. Benih kentang atlantik yang berada di Koppotran diambil dari penangkar milik swasta yaitu Kenhouse, sedangkan benih kentang granola diambil dari penangkar milik pemerintah yaitu Balai Benih Induk Kentang (BBI) di Pangalengan. Pembelian benih tersebut dilakukan dari satu sampai dua kali dalam satu musim tanam.

Koppotran membeli benih di BBI dan Kenhouse karena sudah dipercaya 
oleh petani di sekitar Kecamatan Kertasari dan benih yang dijual BBI dan kenhouse sudah tersertifikasi.

Pupuk yang digunakan oleh koppotran yaitu pupuk kandang dan pupuk kimia. Pupuk kandang terdiri atas organik, kotoran ayam dan portas; sedangkan pupuk kimia terdiri atas urea, SP36, NPK ponska dan captan. Pupuk kandang digunakan setiap satu kali pakai dalam satu musim tanam. Besarnya pemakaian pupuk kandang berkisar 20-30 ton/ha.

Pupuk kimia digunakan setiap dua kali pakai dalam satu musim tanam. Besarnya pamaikan pupuk kimia harus disesuaikan dengan kebutuhan tidak boleh melebihi pemakaian pupuk kandang karena apabila terlalu banyak memakai pupuk kimia tidak baik untuk pertumbuhan tanaman kentang.

Pestisida yang dipakai koppotran terdiri atas tiga kategori, yaitu fungisida, insektisida dan akarisida. Pemakaian fungisida dapat dilakukan 15-18 kali pakai untuk satu kali penanaman. Jenis fungisida yang digunakan yaitu klorotalonil dan previcure. Selain pemakaian fungisida, ada pula insektisida untuk mengusir hama atau serangga yang akan merusak tumbuh kembang kentang pada saat budidaya dilakukan. Pemakaian insektisida dapat dilakukan 8 kali pakai untuk satu kali penanaman.

Alat dan mesin pertanian sangat dibutuhkan dalam sistem input karena dapat membantu berjalannya budidaya kentang sampai ke hasil panen. Alat pertanian yang dibutuhkan pada saat budidaya kentang yaitu cangkul, traktor tangan dan mesin sprayer. Penggunaan traktor tangan satu kali dalam satu musim tanam. Cangkul digunakan empat kali dalam satu musim tanam, sedangkan mesin sprayer digunakan 15 kali dalam satu musim tanam.

2. Produksi Pertanian Primer (On Farm)

\section{A. Pemilihan Lokasi}

Lahan bukan bekas tanaman sejenis atau sefamili, lahan kentang harus terbuka sehingga matahari langsung menyinari tanaman kentang serta dekat dengan mata air.

B. Penentuan Waktu Tanam

Pengamatan dilakukan saat ketersediaan air secara alami di lahan pada saat musim hujan tiba dan akhir musim hujan. Sarana prasarana irigasi yang disiapkan seperti pompa dan sumur bor.

C. Penyiapan Lahan

Mencangkul atau membajak tanah sedalam $30 \mathrm{~cm}$ sampai gembur, dibiarkan 
selama 15 hari untuk memperbaiki sirkulasi udara dan kadar tanah. Tanah digemburkan kembali, kemudian diratakan. Garitan dibuat dengan kedalaman kurang lebih $25 \mathrm{~cm}$. Jarak antar garitan $73 \mathrm{~cm}$. Pada lahan miring garitan dibuat melintang dari arah kemiringan lahan.

D. Penyiapan Benih

Benih yang digunakan adalah benih varietas $\mathrm{G} 2$ dan G3 yang bersertifikat dan diambil dari Balai benih Induk Kentang di Pangalengan.

E. Penanaman, Pemupukan Dasar dan Penyulaman

Benih yang diperlukan dengan memakai jarak tanam $73 \mathrm{~cm}$ adalah 1.500 $\mathrm{kg} / \mathrm{ha}$ dengan anggapan umbi benih berbobot sekitar 60 gr. Lubang tanam dibuat dengan kedalaman $8-10 \mathrm{~cm}$. Pupuk kandang yang sudah tercampur dengan baik sebanyak 20-30 ton/ha, dicampur pada tanah bedengan atau pada lubang tanam kurang lebih seminggu sebelum tanam. Pupuk kimia (Phonska $500 \mathrm{~kg}$ dan SP36 $200 \mathrm{~kg}$ ) total pupuk kimia yang dipakai $700 \mathrm{~kg} / \mathrm{ha}$ diberikan pada setiap lubang tanam. Selanjutnya, benih dan pupuk ditimbun dengan tanah sehingga membentuk guludan setinggi kurang lebih $10 \mathrm{~cm}$ dari permukaan tanah. Mulsa jerami perlu dihamparkan di bedengan jika kentang ditanam di dataran sedang. Penyulaman dilakukan setelah tanaman berumur 15 hari.

F. Pengairan

Air dihisap dan dialirkan dari sumber air dengan menggunakan pompa air dan dialirkan dengan selang ke areal pertanaman dengan mengairi selokan sampai areal lembab sekitar 15-20 menit.

G. Pemupukan Susulan dan Pembumbunan

Ketika tanaman berumur 21 hari dilakukan penyiangan kemudian dipupuk dengan pupuk urea sebanyak urea $150 \mathrm{~kg}$ dan KCL sebanyak $300 \mathrm{~kg}$ diberikan ke dalam lubang pada jarak $10 \mathrm{~cm}$ dari batang tanaman kentang. Kemudian dilanjutkan dengan pembumbunan. Setelah tanaman berumur 45 HST ditambahkan pupuk urea dan KCL masing-masing dengan dosis $200 \mathrm{~kg}$ dan 100 kg. Aplikasi pupuk cair tiga kali selama penanaman selang 15 hari satu sama lain. Pada umur 35-40 HST dilakukan pembumbunan II, dengan mencangkul tanah diantara guludan atau parit kemudian dinaikkan ke atas guludan sebelah kanan dan kiri parit.

H. Penyiangan, Sanitasi, Pemangkasan

Penyiangan hara dilakukan pada fase kritis yaitu vegetatif awal dan pembentukan umbi. Penyiangan 
dilakukan secara berkelanjutan minimal dua kali selama masa penanaman, sebaiknya dilakukan 2-3 hari sebelum atau bersamaan dengan pemupukan susulan dan pembumbunan. Penyiangan dilakukan pada saat tanaman berumur 2030 HST.

I. Penentuan Saat Panen

Saat panen yang tepat pada tanaman kentang ditandai dengan perubahan warna daun dari hijau segar menjadi kekuningan yang bukan disebabkan oleh penyakit, batang tanaman telah berwarna kekuningan dan agak mengering, kulit umbi tidak cepat mengelupas bila digosok dengan jari. Kentang biasanya mulai dipanen pada umur 90-180 hari pada varietas granola.

\section{J. Panen}

Bongkar guludan dengan cara mencangkul tanah di sekitar umbi secara hati-hati, lalu mengangkatnya sehingga umbi ke luar dari dalam tanah dan diletakkan di permukaan tanah agar terjemur matahari. Lakukan sortasi awal kemudian dimasukkan ke keranjang dan dibawa ke tempat pengumpulan hasil panen. Hasil panen ada yang dikumpulkan di gudang ada yang langsung diangkut ke pasar. Hindari kerusakan mekanis saat panen.

\section{Hasil Pengolahan Pertanian}

Koppotran hanya mengelola kentang menjadi kentang goreng karena pembuatannya yang mudah dan tidak memerlukan pengeluaran yang banyak. Pengolahan tersebut dilakukan di rumah pribadi dan dikelola oleh keluarga sendiri. Pembuatan kentang goreng dapat menghasilkan keuntungan yang tinggi apabila diperjualbelikan di pasar. Kentang goreng dibuat pada saat harga kentang lagi menurun agar pendapatan lebih menguntungkan banyak dibandingkan dengan harga kentang lagi tinggi pendapatan tidak jauh beda dengan modal. Selain membuat kentang goreng, koppotran membuat keripik kentang untuk menambah pendapatan. Pembuatan keripik tersebut dibantu oleh Kelompok Wanita Tani (KWT) di sekitar Kecamatan Kertasari yang dibantu oleh ibu-ibu rumah tangga. Olahan keripik kentang sangat bervariasi seperti rasa coklat, original dan keju.

\section{Pemasaran Hasil Pertanian}

Koppotran menjual umbi kentang varietas gronola karena kentang granola yang biasa dikonsumsi masyarakat dan dijual di pasar tetapi koppotran menjual umbi kentang hanya ke tengkulak dengan berat 30 ton/hari dengan harga $\mathrm{Rp}$ 7.500/kg lalu tengkulak jual ke pasar 
induk di Kramat Jati, Tangerang, Cibitung dan pasar induk lainnya dengan harga Rp 8.000/kg. Sedangkan umbi kentang varietas atlantik dijual ke PT. Indofood karena persetujuan melalui MOU bahwa kentang atlantik hanya diperjualbelikan kepada PT. Indofood dengan harga Rp8.000/kg.

5. Lembaga Penunjang

Penyuluh jadi fasilitator bagi koppotran untuk mendapatkan bantuan pemerintah berupa barang maupun pelatihan. Koppotran berhubungan dengan kelompok tani lain mendiskusikan masalah suplai benih, seperti dengan kelompok tani paguyuban Pangalengan sebagai penyedia benih kentang.

Lembaga yang bekerjasama dengan koppotran yaitu JICA untuk melatih budidaya kentang yang difasilitasi pemerintah dan Kenhouse untuk pemberdayaan benih bermutu dan bersertifikat. Koppotran membeli bahan input dan alat pertanian di toko pertanian sekitar Desa Cikembang. Apabila tidak ada di desa, maka akan membeli di Bandung. Koppotran belum dibantu oleh lembaga keuangan manapun.

Koppotran tidak menjual langsung ke pasar induk tetapi melalui perantara tengkulak karena perjalanan untuk langsung dijual di pasar induk cukup menguras tenaga dan biaya dengan jarak tempuh yang begitu jauh dan lebih untung dijual langsung ke tengkulak.

\section{Analisis Usahatani}

Pemilik Koppotran memberikan rincian dana mengenai pengeluaran dalam budidaya kentang sebagai berikut dapat dilihat pada Tabel 1.

A. Tingkat Kelayakaan Usahatani (R/C)

Analisis ini apabila nilai $\mathrm{R} / \mathrm{C}>1$, maka usaha tersebut dikatakan layak untuk diusahakan, karena besarnya pendapatan lebih besar dari besarnya biaya yang dikeluarkan. Perhitungan hasil analisis pendapatan dengan biaya $(\mathrm{R} / \mathrm{C})$ dapat dilihat sebagai berikut:

$$
\begin{aligned}
& \mathrm{R} / \mathrm{C}=\frac{\text { Total Pendapatan }}{\text { Total Biaya produksi }} \\
& =\frac{126.400 .000}{100.000 .000}=1,26
\end{aligned}
$$

Berdasarkan uraian di atas, dapat disimpulkan bahwa usahatani kentang dinyatakan layak untuk diusahakan. Hal ini dapat dilihat dari perbandingan total pendapatan dan total biaya yang lebih besar dari satu, yaitu memiliki angka 1,26 $>1$. 
Tabel 1. Biaya Usahatani Kentang

\begin{tabular}{|c|c|c|c|c|c|}
\hline No & Komponen & Volume (Ha) & Satuan & Harga (Rp) & Jumlah \\
\hline $\mathbf{A}$ & Sarana Produksi & & & & \\
\hline 1 & Sewa Lahan & 1 & $\mathrm{Ha}$ & 250.000 & 6.250 .000 \\
\hline 2 & Benih Kentang Granola & 1.300 & $\mathrm{Kg}$ & 15.000 & 19.500 .000 \\
\hline \multirow[t]{6}{*}{3} & Pupuk & & & & \\
\hline & Kandang & 20.000 & $\mathrm{Kg}$ & 750 & 15.000 .000 \\
\hline & SP36 & 300 & $\mathrm{Kg}$ & 1.750 & 525.000 \\
\hline & UREA & 200 & $\mathrm{Kg}$ & 2.000 & 400.000 \\
\hline & NPK Ponska & 500 & $\mathrm{Kg}$ & 2.500 & 1.250 .000 \\
\hline & Captan & 2.000 & $\mathrm{Kg}$ & 500 & 1.000 .000 \\
\hline \multirow[t]{4}{*}{4} & Pestisida & & & & \\
\hline & Insektisida & 20 & Liter & 150.000 & 3.000 .000 \\
\hline & Fungisida & 40 & $\mathrm{Kg}$ & 150.000 & 6.000 .000 \\
\hline & Nematisida & 25 & $\mathrm{Kg}$ & 30.000 & 725.000 \\
\hline \multirow[t]{5}{*}{5} & Peralatan/sarana & & & & \\
\hline & Tali rapia & 50 & Roll & 30.000 & 1.500 .000 \\
\hline & Terpal $6 \times 8 m$ & 1 & Buah & 200.000 & 200.000 \\
\hline & Ajir & 15.000 & Batang & 200 & 3.000 .000 \\
\hline & \multicolumn{3}{|c|}{ Total Sarana Produksi } & & 58.150 .000 \\
\hline $\mathbf{B}$ & Biaya Tenaga Kerja & & & & \\
\hline \multirow[t]{9}{*}{1} & Biaya Garap/Pemeliharaan & & & & \\
\hline & Pengolahan Lahan & 40 & Hok/L & 35.000 & 1.500 .000 \\
\hline & Pembuatan Guludan & 20 & Hok/L & 35.000 & 700.000 \\
\hline & Pemupukan Dasar & 40 & Hok/P & 25.000 & 1.000 .000 \\
\hline & Penanaman & 35 & Hok/L & 35.000 & 1.225 .000 \\
\hline & Pemupukan Susulan & 40 & Hok/L & 35.000 & 1.400 .000 \\
\hline & Penyiangan & 40 & Hok/L & 35.000 & 1.000 .000 \\
\hline & Penyemprotan OPT & 35 & Hok/L & 35.000 & 1.225 .000 \\
\hline & Bahan Bakar & 25 & Liter & 8.000 & 200.000 \\
\hline \multirow[t]{8}{*}{2} & Biaya Panen dan Pasca Panen & & & & \\
\hline & Panen & 80 & Hok & 25.000 & 1.000 .000 \\
\hline & Biaya Angkut Produksi & 2.000 & $\mathrm{Kg}$ & 200 & 4.000 .000 \\
\hline & Biaya Tunggu & 20 & Hok & 50.000 & 50.000 \\
\hline & Mandor & 30 & Hok & 40.000 & 40.000 \\
\hline & \multicolumn{3}{|c|}{ Total Tenaga Kerja } & & 16.450 .000 \\
\hline & \multicolumn{3}{|c|}{ Total Biaya Produksi } & & 74.600 .000 \\
\hline & \multicolumn{3}{|c|}{ Nilai Total Produksi } & & 100.000 .000 \\
\hline
\end{tabular}

B. Keuntungan Usahatani

Keuntungan usaha adalah pendapatan total dikurang dengan biaya total dari usahatani kentang. Secara matematis dapat ditulis sebagai berikut (Rahim dan Hastuti, 2007):

$$
\begin{aligned}
\pi & =T_{r}-T_{C} \\
\pi & =\operatorname{Rp} 126.400 .00-\operatorname{Rp} 100.000 .000 \\
& =\operatorname{Rp} 26.400 .000
\end{aligned}
$$

Berdasarkan uraian di atas, dapat disimpulkan bahwa usahatani kentang dinyatakan memiliki total keuntungan yang diterima oleh Koppotran yaitu sebesar Rp 26.400.000.

C. Harga dan Peluang Pasar

Peluang pasar di Koppotran untuk penjualan kentang sangat luas di pasar induk. Koppotran dalam menjual kentang granola selalu disamakan dengan petani 
lain yang menjual ke tengkulak dengan kisaran harga Rp 7.500/kg; sedangkan kentang atlantik dijual ke PT. Indofood dengan kisaran harga Rp 8.000/kg.

1. Analisis Ekologi Usahatani

Teknologi pertanian di lahan miring di Kecamatan Kertasari merupakan suatu pola agroforestry, karena didalamnya terdapat jalur-jalur tanaman seperti kopi, coklat, jeruk, dan buah-buahan. Jalur tanaman tahunan tersebut ditanami dengan tanaman semusim seperti kentang. Contoh jenis tanaman yang dapat digunakan untuk penyanggah agar mengurangi erosi tersebut adalah pohon cemara, mahoni dan turi.

Menjaga kelestarian lingkungan di sekitar Kecamatan Kertasari yaitu dengan menjunjung prinsip ekologi (Departemen Kehutanan,1987), yaitu:

1. Memperbaiki kondisi tanah dengan mengurangi pupuk kimia yang berlebihan saat budidaya kentang.

2. Mengoptimalisasikan ketersediaan dan keseimbangan zat hara tanah.

3. Membatasi kehilangan hasil panen dengan pencegahan erosi yaitu membuat teras guludan karena Kecamatan Kertasari memiliki tanah dengan kemiringan 10-50\%.

Masalah usahatani di daerah berlereng adalah sering terjadinya erosi yang semakin besar apabila tidak diringi dengan teknik konservasi. Erosi sangat merugikan produktivitas lahan karena dalam waktu singkat lapisan tanah atas yang subur akan hilang.

2. Analisis Sosial Usahatani

A. Sumber Daya Manusia

Menurut penuturan pemilik koppotran bahwa di Kecamatan Kertasari mayoritas warganya bekerja sebagai petani kentang dan buruh tani kentang karena sentra produksi kentang terletak di Kecamatan Kertasari. Apabila petanipetani di sekitar Kecamatan Kertasari memanfaatkan budidaya kentang akan mendapatkan keuntungan untuk pemasukan pribadi. Pemilik koppotran mengarahkan anaknya menjadi petani kentang untuk meneruskan usahatani orang tuanya.

Ada pula petani yang tidak memaksakan anaknya menjadi petani kentang juga, dan membebaskan anaknya ingin bekerja diluar sektor pertanian tetapi orangtua mengharapkan anaknya bisa membantu usahatani kentang yang sudah dirintis dari dahulu kala oleh keluarganya.

B. Pola Konsumsi Masyarakat

Masyarakat Kecamatan Kertasari menjadikan kentang sebagai konsumsi pangan kedua setelah beras karena 
kentang mudah didapatkan dan mudah untuk diolah serta setiap keluarga di Kecamatan Kertasari sebagian besar yaitu menjadi petani kentang.

C. Kepadatan Penduduk

Tingginya kepadatan penduduk di Jawa Barat disertai dengan sulitnya mencari lapangan kerja, memaksakan petani untuk memperluas tanah garapannya ke lahan hutan, seperti di Koppotran tanah yang dimilikinya sudah tidak mencukupi kebutuhan budidaya maka menggarap budidaya kentang di lahan hutan yang seharusnya lahan hutan dijaga dengan baik.

\section{Model Usahatani}

Budidaya kentang sebenarnya merusak kelestarian lingkungan dan membuat laju erosi karena tidak memperhatikan kaidah-kaidah tentang konservasi tanah di lereng miring. Cara untuk pelestarian lingkungan dan agar tidak terjadi erosi berkepanjangan maka pemerintah membuat beberapa kegiatan yaitu, penanaman tanaman tahunan seperti tanaman durian, kopi, dll. Selain itu, melakukan reboisasi dan juga melibatkan masyarakat sekitar dengan membersihkan daerah aliran sungai dengan mengambil sampah yang bertebaran sembarangan dan menciptakan semboyan“Citarum Harum”

Koppotran pada umumnya sama dengan petani kentang biasa namun namun yang membedakan ada pinjaman pupuk dan pestisida. Pada saat pinjam meminjam agar terhindar dari riba, maka dilakukan akad agar sah. Pola tanam konservasi lingkungan baru diterapkan sebagian yaitu dengan pembentukan terasering dan kemiringan lahan. Manajemen konservasi sudah dilakukan pada beberapa lokasi, khususnya untuk lahan pribadi adapun yg ditanam dilahan PTPN VIII arah guludan harus disesuaikan dengan tanaman kopi dan kayu putih, terkadang sesuai dengan arah kemiringan terkadang tidak. Hampir sebagian besar lahan ditanami tanaman semusim di hulu sungai citarum dan saat ini Koppotran mengikuti pola tanam harus dari pemerintah terutama pihak TNI dengan cara tumpangsari yang ditanami tanaman kopi dan kayu.

\section{KESIMPULAN DAN SARAN}

\section{Kesimpulan}

Model usahatani di Kecamatan Kertasari merupakan pertanian konvensional yang menggunakan alat pertanian masih menggunakan tenaga manusia dan hewan. Koppotran memiliki 
lahan sendiri dan lahan sewa yang sebagian lahannya diiringi dengan teknik konservasi di lahan miring. Tanaman kentang sebenarnya tidak ramah lingkungan karena merusak lingkungan seperti erosi dan untuk menanganinya Koppotran mengikuti pola tanam dari pemerintah terutama pihak TNI dengan cara tumpangsari yang ditanami tanaman kopi dan kayu.

\section{Saran}

1. Masyarakat sekitar harus lebih meningkatkan kepedulian terhadap kelestarian lingkungan sekitar dengan menerapkan teknik konservasi lingkungan dengan reboisasi.

2. Bagi penyuluh, sebaiknya secara rutin sekitar seminggu tiga kali untuk memberikan materi penyuluhan pertanian dengan berbagai metode pengajaran di lapangan untuk meningkatkan pengetahuan dan wawasan petani tentang usahatani di lahan kritis
3. Bagi petani, mengikuti penyuluhan atau kegiatan lain yang mendukung usahatani konservasi pada lahan pertanian.

\section{DAFTAR PUSTAKA}

Direktorat Jendral Pertanian. (2018). Statistik Produksi Holtikultura Tahun 2017. Jakarta: Direktorat Jenderal Holtikultura.

Badan Pusat Statistik. (2017). Produksi

Hortikultura Sayuran dan Buah Semusim Provinsi Jawa Barat.

Fauziah, Y. (2016). Respon Petani Kentang Terhadap Lahan Kritis di Kecamatan Kertasari Kabupaten Bandung. Skripsi. UPI Bandung.

Kementerian Pertanian. (2015). Konsumsi Pangan 2015. Pusat Data dan Sistem Informasi Pertanian.

Sugiyono. (2012). Metode Penelitian Kuantitatif, Kualitatif dan $R \& D$. Bandung: Alfabeta. 